\title{
A Ureteral Inguinoscrotal Hernia from a Pelvic Kidney
}

\author{
Ayse V. Dikmen ${ }^{\mathrm{a}} \quad$ Cagri Guneri $^{\mathrm{b}} \quad$ Serdar Yalcin $^{\mathrm{c}} \quad$ Onur Acikgoz $^{\mathrm{d}} \quad$ Esat Ak $^{\mathrm{e}}$ \\ Sadettin Cetiner ${ }^{f}$ \\ aUrology Clinic, Polatlı Duatepe Government Hospital, Ankara; bUrology Clinic, Liv Hospital, Ankara; cUrology Clinic, Agri Military \\ Hospital, Agri; dUrology Clinic, Etlik Zubeyde Hanım Gynecologic Training and Research Hospital, Ankara; eUrology Clinic, 29 Mayıs \\ Government Hospital, Ankara; 'Urology Clinic, GATA, Ankara, Turkey
}

\section{Key Words}

Inguinoscrotal hernia $\cdot$ Ureter $\cdot$ Ureteral herniation • Ureteroureterostomy $\cdot$ Scrotum

\begin{abstract}
A 74-year-old male patient with prostate cancer under remission was admitted with left inguinoscrotal swelling. He underwent scrotal ultrasound demonstrating a giant inguinoscrotal hernia. Contrast-enhanced computerized tomography of the abdomen and pelvis demonstrated a left pelvic kidney associated with severe hydroureteronephrosis secondary to a ureteral inguinoscrotal hernia. Upon exploration with left inguinal incision, a paraperitoneal ureteral inguinoscrotal hernia and a hypertrophic left spermatic cord were observed. The elongated and tortuous left ureter, being pulled down to the scrotum by the hernia, was released from the herniating tissues fullfilling left hemiscrotum. The ureter was tapered followed by ureteroureterostomy. The accompanying left spermatic cord was excessively elongated and curled, necessitating cordectomy. The hernia was repaired with prolene mesh after removal of herniating peritoneal tissue. This is a rare case of a paraperitoneal ureteral inguinoscrotal hernia of the left pelvic kidney.
\end{abstract}

Copyright $\odot 2017$ S. Karger AG, Basel

\section{KARGER}

Fax +4161306 1234

E-Mail karger@karger.com Accessible online at:

www.karger.com www.karger.com/cur

\section{Introduction}

Pelvic kidney is a relatively rare entitiy and the incidence is about $1 / 2,200$ to $1 / 3,000$ [1]. The tortuous ureter is often associated with a pelvic kidney hinders deflection of the flexible ureteroscope, potentially limiting access [1]. Inguino scrotal herniation of the ureter (native or transplanted) is extremely rare [2-4]. Eighty percent are paraperitoneal, where the hernia has peritoneum antero-medially in addition to the ureter (and other organs) adherent to the postero-lateral peritoneum as part of the sac [5]. There are usually no symptoms unless obstruction causes pain and hydronephrosis [6]. Extraperitoneal hernias have no sac, containing fat and ureter only, and take origin from failure of ureteric differentiation from the mesonephric duct [2]. During embriogenesis, adhesions between the developing ureter and genital ligaments can somehow pull the ureter down into a hernia [2]. In a current study, 190 cases of inguinal hernia, being associated with urological findings, such as herniation of the bladder, ureter, and diverticulum were evaluated [7]. The high-risk patients were male, obese, older than 50 years and had symptoms that indicated urological pathologies to a physician [7]. 


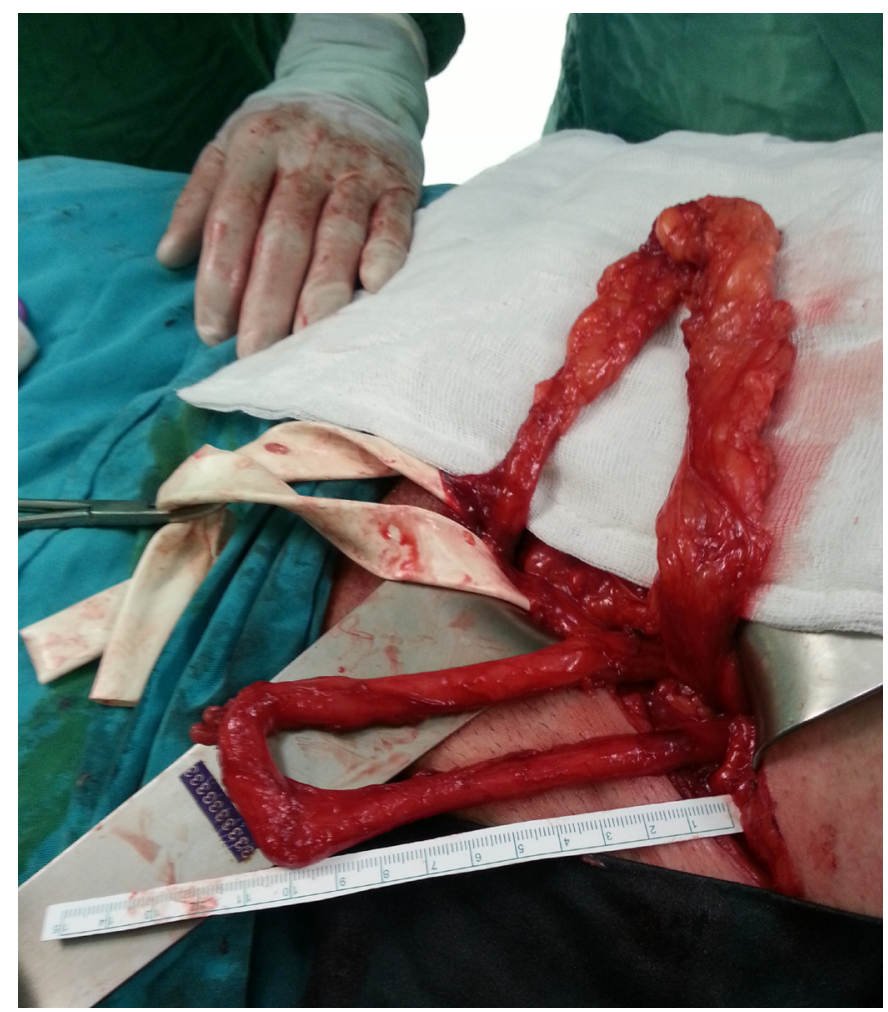

Fig. 1. Peroperative image of left ureter (downward) being excessively elongated and tortuous and the left spermatic cord (upward).

\section{Case Report}

Pelvic kidney is the most common type of renal ectopia. We present a different clinical presentation of a 74-year-old male patient with an inguinoscrotal hernia. Male patient with prostate cancer under remission was admitted with left inguinoscrotal swelling. He underwent scrotal ultrasound demonstrating a giant inguinoscrotal hernia. At the beginning, a routine operation of repairing his inguinal hernia was decided. His creatinine was $1.1 \mathrm{mg} / \mathrm{dl}$ and hemoglobin was $13.5 \mathrm{~g} / \mathrm{dl}$. He had been getting hormonotherapy for localized prostate cancer under control. For further evaluation of his prostate cancer, a contrast-enhanced computerized tomography (CT) of the abdomen and pelvis was taken and demonstrated a left pelvic kidney associated with severe hydroureteronephrosis secondary to a left ureteral inguinoscrotal hernia. On CT scans, the descending ureter, which was contrast-enhancing next to the inguinoscrotal hernia sac, was visible. On the day of operation, cystoscopy was carried on and a $3 \mathrm{~F}$ ureter catheter was sent on a guidewire through the left ureteric orifice. After $15 \mathrm{~cm}$ length, the catheter could not move forward and it was left within the orifice, attached to the Foley catheter. Upon exploration with left inguinal incision by a team work of surgeons from urology and general surgery clinics, the hernia sac was extending through the left inguinoscrotal space. When the hernia sac was dissected, a paraperitoneal left ureteral inguinoscrotal hernia and

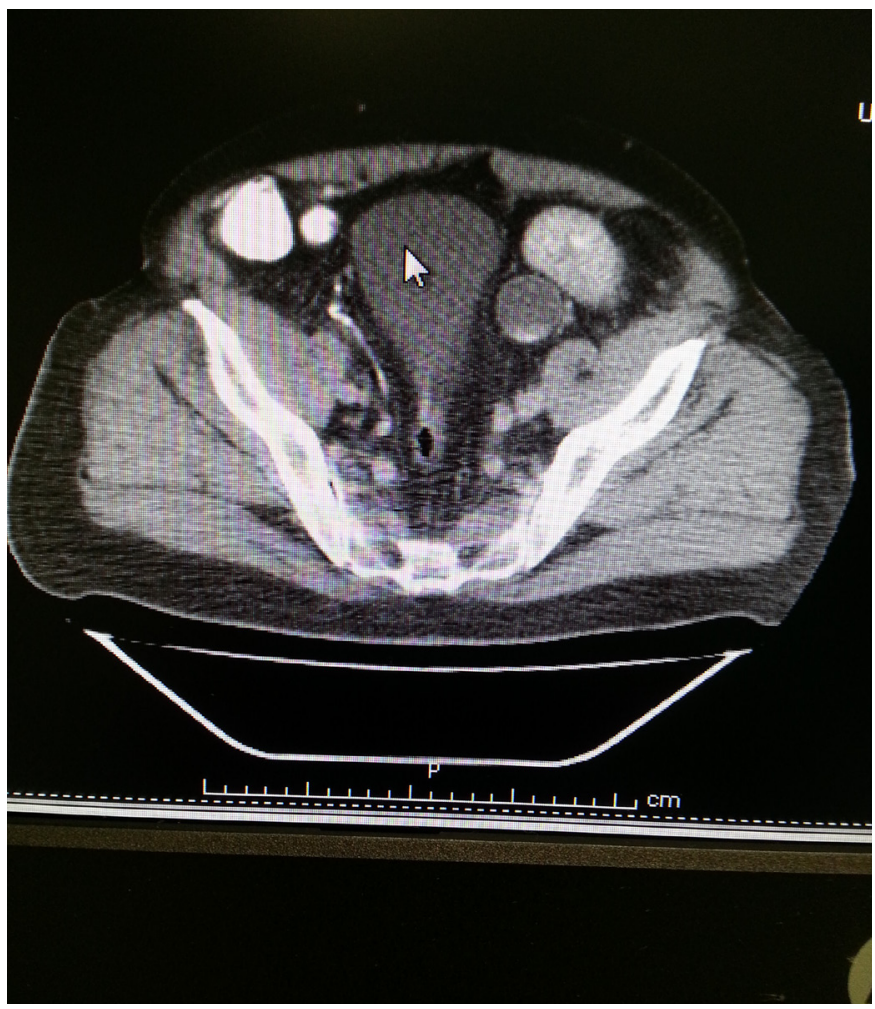

Fig. 2. CT of left pelvic kidney and the dilated left ureter.

a hypertrophic left spermatic cord were observed. The elongated and tortuous left ureter, which had been pulled down to the scrotum by the hernia, was released from the herniating tissues fullfilling left hemiscrotum. Peroperatively, left pelvic kidney was able to be palpated with its prominent extrarenal pelvic structure. The excesive part of the ureter was tapered, followed by end-to-end ureteroureterostomy with 3/0 V-Lock barbed suture and placing a $6 \mathrm{~F} 26 \mathrm{~cm}$ double $\mathrm{J}$ stent. The excellent position of the stent was controlled under scope. The accompanying left spermatic cord was also released from the sac and was excessively elongated and curled, necessitating cordectomy in order to prevent future risk of torsion. A Jackson-Pratt drain was placed within the site of operation. The hernia was repaired with prolene mesh after removal of herniating peritoneal tissue. During recovery, the patient had no complications and the drain was removed on the first postoperative day. He was externed well on the second postoperative day.

\section{Discussion}

This is a rare case of a paraperitoneal ureteral inguinoscrotal hernia of a patient with left pelvic kidney in the literature. We present a rare but important case, in which significant peri-operative care should be taken 
when undertaking inguinal hernia surgery in order to avoid damage to the ureter of the left pelvic kidney. Although some cases have incidental signs, in differential diagnosis attention should be paid during surgery of patients with inguinal hernia and evidence of hydronephrosis of pelvic kidney. The ectopic kidney is thought to be no more susceptible to disease than the normally positioned kidney, except for the development of calculi and hydronephrosis [1]. Because of the greater risk of damaging aberrant vessels, the pelvic kidney presents special treatment challenges [1]. In the literature, there are rare cases, described with a paraperitoneal inguinal hernia of ureter, presenting as an incidental finding during evaluation for acute renal failure and ultrasound finding of hydronephrosis [8]. Ureteral herniation is rare, often misdiagnosed with probable surgical complications [9]. Until 1992, 128 cases of ureteral herniation were reported, 54 $(42 \%)$ of which were in the inguino scrotal region [9]. Two types of uretero inguinal hernias can be identified: the more frequent and acquired paraperitoneal type, associated with other herniated abdominal structures paraperitoneal and always presenting a peritoneal hernia sac and the extraperitoneal type, which is very uncommon, congenital and never associated with a true peritoneal sac but composed only of the ureter [9]. Although most of the presenting cases are incidental ones, encountered during surgery, some cases in the literature could have attended with hydronephrosis and ureteric obstruction secondary to an ureteroinguinal herniation [10].

\section{Conclusion}

To the best of our knowledge, this is one of the rarest cases of paraperitoneal ureteral inguinoscrotal hernia from a pelvic kidney. Surgical interventions dealing with this entity are still challenging and require excellent surgical skills.

\section{References}

1 Cinman NM, Okeke Z, Smith AD: Pelvic kidney: associated diseases and treatment. J Endourol 2007;21:836-842.

2 Haywarda A, Al-sam R, Oades G, Fraser M, Rajan D: Uretero-inguinal herniation: a rare complication of ureteral duplication. World J Nephrol Urol 2012;2-3:88-90.

3 Odisho AY, Freise CE, Tomlanovich SJ, Vagefi PA: Inguinal herniation of a transplant ureter. Kidney Int 2010;78:115.

4 Sripathi S, Rajagopal K, Kakkar C, Polnaya A: Inguinoscrotal ureteral hernia diagnosed on micturating cystourethrography. Indian J Radiol Imaging 2011;21:199-201.
5 Bertolaccini L, Giacomelli G, Bozzo RE, Gastaldi L, Moroni M: Inguino-scrotal hernia of a double district ureter: case report and literature review. Hernia 2005;9:291-293.

6 Massoud W, Eschwege P, Hajj P, Awad A, Iaaza LA, Chabenne J, Hammoudi Y, Droupy S, Benoit G: Hydronephrosis secondary to sliding inguinal hernia containing the ureter. Urol J 2011;8:333-334.

7 Oruç MT, Akbulut Z, Ozozan O, Coskun F: Urological findings in inguinal hernias: a case report and review of the literature. Hernia 2004;8:76-79.
$8 \mathrm{Lu}$ A, Burstein J: Paraperitoneal inguinal hernia of ureter. J Radiol Case Rep 2012;6:2226.

9 Giglio M, Medica M, Germinale F, Raggio M, Campodonico F, Stubinski R, Carmignani G: Scrotal extraperitoneal hernia of the ureter: case report literature review. Urol Int 2001;66:166-168.

10 McKay JP, Organ M, Bagnell S, Gallant C, French C: Inguinoscrotal hernias involving urologic organs: a case series. Can Urol Assoc J 2014;8:E429-432. 